\title{
Relationship between Fluctuated Exports and Economic Growth of Pakistan
}

\author{
Uzma Rasool Khan ${ }^{1,2}$ \\ ${ }^{1}$ Bahria University, Karachi Campus, Pakistan \\ ${ }^{2}$ Department of Business Administration, Jinnah University for Women, Pakistan \\ Corespondence: Uzma Rasool Khan, Department of Management Sciences, Bahria University Karachi Campus, \\ House number B-94, Karachi, Pakistan. Tel: 333-382-6038. E-mail: uzmarasoolkhan@gmail.com
}

Received: July 10, 2013

Accepted: October 11, 2013

Online Published: October 15, 2013

doi:10.5539/ijbm.v8n21p108

URL: http://dx.doi.org/10.5539/ijbm.v8n21p108

\begin{abstract}
As manufacturing units, small medium enterprises, multinational organizations, entrepreneurship based organizations are considered as the engine of growth, barometer, building block of the economy as well as the backbone of the economy of any country, exactly like that exports of country is considered as an indicator or a source which reflects the internal economic stability and capability of a national progress. Pakistan is a country which is full of national resources, reserves and talent but due to manifolds factors like domestic issues, bad governance, unachieved goals, insufficient industrial infrastructure, less skilled labor, brain drain, lack of exposure and access into the international market are the most important factors behind the stagnant and fluctuated exports of Pakistan. So for the purpose to detect the variables affecting exports of Pakistan four of the variables have been taken as an independent variables and exports is taken as a dependent variable, While Fixed investment capital and inflation showed strong significant relationship statistically and explored that to reduce the inflation rate and to increase the fixed investment capital can work as the biggest contributor for the growth of exports and economic development of Pakistan.
\end{abstract}

Keywords: exports, relative exchange rate, gross domestic products, inflation, capital

\section{Introduction and Background of the Study}

If we move towards the background and history of export, the movement and exchange of goods are considered as one of the oldest business of this world and now in this era due to amazing information technological related facilities, mediums of rapid transportation, development of proper passages and availability of convenient facilities to deliver the products and off course availability of radical technological and transportation facilities give exposure into the international world more easily.

An export gives a guarantee of financial economic stability of a country, this is one of the ways to suck money from the economies of diversified nations and inject into the home economy from the host economy, so through the help of this foreign exchange the home country started progressing.

For to prove the mentioned statement we can do an analysis and review of the progress of china and America, If looks towards the physical average age of the multinationals corporations of America, found out that their ages are is in between 90 to 100 years, American industrial revolution focused on European planning rather than Trukese planning which usually developing and underdeveloped countries used to do, Initially America emphasize on the development of cottage industries and small medium enterprises detected the theory that, small industries can be the a bigger one in the long run and can be transformed into a world recognized multinationals and not only be able to fulfill the requirements of the home country and can helps to increase the economic stability and progress of the their nation, in fact through the help of industrial revolution they can able to pledge the needs of the others countries. America and Germany highly emphasize on the importance of exports and than in a very short span of time they entered into the line of very well developed economies.

On the other hand the revolution of Chinese products presence into the international market is also a tremendous magical story of exports in this world, china was a drug addicted and sleeping nation. In the history of this world, not any nation progressed in that way as the china have done, for the purpose to increase the economic development of a country and exports china highly focused on the development of industrial infrastructure, ensure to make the availability of cheaper rate and skilled labors with the help of high level governmental support, China's exports flourished through their effective strategies to capture the exports markets like through 
customization, variation and categorization of products as per the needs and demands of the country, that vary from country to country and from customer to customer in term of prices and quality. China is highly progressing through their exports and the revenue they are generating through their strategic plan.

Exports dominance of the country in the regional and international market reflects its internal strength, capability and aspects of good governance and shows that they are not only capable to fulfill their own country requirement, in fact they can also be able to fulfill requirements of other countries as well and when exports production fulfill the international standards, this helps to create goodwill and image of the country in the international market and show that this country is not being able to fulfill their own requirement but also they can able to fulfill the requirements of others as well.

\subsection{Research Objectives}

Objective of the research is to evaluate and investigate the factors effecting exports of Pakistan and the purpose of the study is to detect the basic model of factors effecting exports of Pakistan, to detect that through this situation what sort of negativity and fluctuation can be predicted and occurred on the exports of the country.

\section{Theoretical and Empirical Review of Literature}

On the topic of worlds exports and exports in Pakistan, a substantial literature with a diversified horizon is available, with a demonstration on the present and past situation of the country explaining the reasons of fluctuation on the exports of Pakistan through different angles and researcher explored some of the internal and external factors as the most exponential factors creating fluctuations and uncertainty towards Pakistan's exports market.

Nurkse (1958) highly emphasize on the importance of exports in term of economic stability of a country and focus on that this is specially very beneficial for growing and developing economies, and helps to create sustained economic expansion through monitoring of exports procedures

Laldor (1967) detected that development of new industrial units leads to increase of production and industrial goods, and documented that there is a strong relationship between high productivity and growth of exports.

Amjad \& Mahmood evaluated the problems which exports sector of Pakistan is facing due to the domestic issues, poor infrastructure, law and order situation $\&$ disability to face competition into the international market as well as some of the other factors like lack of proper awareness of the international quality standards and starve of other inputs like fuel \& shortage of working capital creating a big flaw and decline towards the exports of Pakistan.

Shirazi \& Manap identified and analyze the difference between the proactive entrepreneurship based organizations and the conservative or resistance based organizational approach towards entrepreneurial trends, study proved that entrepreneurial based organizations can better compete into the international market through their value added products, and can able to meet the challenges of international market trading environment.

Shahbaz, Azim \& Ahmed identified that international market demand creates fluctuation on the demands needs of exports of Pakistan, international circumstances create positive and negative effects on the exports of Pakistan, international market looks towards Pakistan for value added products, those should be full of diversification, variety and variation, so if Pakistan shifts its focus from primary, semi-manufactured and high quality value added products, than they can better compete into the international market and increase its exports efficiency.

Hamid \& Hayat conducted a study and highlight the problems, both external and internal, revealed that internal issues of Pakistan are more complicated as compare to the external issues, those are creating hurdles for exporters and investors to move towards the international trading, one of the worst internal issue is related to the energy crises, functional and environmental barriers etc, while on the other side industries are facing external obstacles while doing exports like technological related issues, inability to adopt and understand the procedures and regulations of exports, complicated exports procedures, less educated to meet the criteria of international buyers in term of new product development and its specification.

Okpara attempted to detect the relationship between economic growth and exports in the developing countries and evaluate that proper exports highly depends on the proper availability of resources, technological facilities, production efficiency, proper working on economies of scales are the necessary factors to work on specially for a countries like Bangladesh, Nepal and Pakistan.

Bader investigated the ratio of exports difference between the developed and the developing countries and proves through statistics that international trade and cross border investments helps to stimulate the economic growth of a country with a very fast pace and if companies started working on economies of scales they can be 
able to reduce the production and prevent cost, which helps to accelerate the growth of potential revenue through entering into the foreign markets.

Hussain documented on the point that Pakistan can focus on the development of exports on a regional basis through its regional relationships and trade agreement with Afghanistan, India, China and others, trading with regional partners is more convenient and can easily trapped as compare to the other markets due to less logistics and cargo cost and better availability of the resources to understand the environment.

Khattak \& Umair examined and conducted a comparative study between Pakistan and Bangladesh, and detected that on Gross savings of Pakistan, Foreign Direct Investment, Pakistan's GDP, the goods exports and Pakistan gross national expenditures are having positive results and on the other side exports in the form of services showed negative effect on the exports of Pakistan.

Aslam \& Qaisrani demonstrated the effect of positive policies of trade liberalization on the exports of Pakistan and support the view that reduction in trade barriers creates significant effect on the growth of exports, the study is showing positive effect on real exchange rate and world income and negative impact of Foreign Direct Investment on the exports ratio of Pakistan.

Allaro is revolving around the effect of Gross Domestic Product, trade openness and inflation on the exports of Pakistan and emphasize that these factors are having significant effect on growth and development on exports of Pakistan, on the other side focus on the imports of raw material for the purpose to manufacture goods reflects positive sign on the increase in production and exports of high quality products.

\section{Modeling Framework}

Basic model of factors affecting exports of Pakistan

$$
Y=\beta_{o}+\beta_{1} F I C+\beta_{2} G D P+\beta_{3} I N F+\beta_{4} R E R+\epsilon
$$

Exports of Pakistan $=\beta_{1}+\beta_{2}$ Fixed Income Capital $+\beta_{3}$ Rate of Gross Domestic Products effecting Pakistan $+\beta_{4}$ Inflation rate effecting the exports of the country $+\beta_{5}$ Real Exchange Rate $+\epsilon$

$\epsilon=$ Error.

$\mathrm{Y}=$ Exports (Dependent Variable).

FIC=Fixed Income Capital.

$\mathrm{GDP}=$ Gross Domestic Products.

INF=Inflation.

RER=Relative Exchange Rate.

In the above model $\beta_{0}$ is considered as the value of exports in the absence of independent variables, while $\epsilon$ is representing the impact of other unexplained variables those are having effects on the exports (dependent variable) other than the independent variables explained in the model.

\section{Research Methodology}

Data have been collected from the authorized governmental websites, a time series data have been collected for analysis from the year 2000 to 2010, for the purpose to do an analysis on the changing trends of exports of Pakistan, with the help of secondary data, collected and summarized through the sources of State Bank of Pakistan, TIPD, Pakistan economic review and others.

\section{Estimation Results}

Study is focusing on the exports performance of Pakistan, a time series data have been collected from the year 2001 to 2010, and analysis on the basis of regression model have been done to identify the relationship between exports as an independent and fixed investment capital, inflation, gross domestic product and relative exchange rate as an dependent, and their relationships have been studied critically. 
Table 1. Descriptive analysis

\begin{tabular}{cccccc}
\hline \multicolumn{7}{c}{ Sample: 2001 2010} \\
\hline Lean & LOG(ET) & LOG(FIC) & LOG(GDP) & LOG(INF) & LOG(RER) \\
Median & 1.251415 & 2.826922 & 1.490002 & 1.996904 & 4.602391 \\
Maximum & 1.242453 & 2.780858 & 1.479275 & 2.048770 & 4.597055 \\
Minimum & 1.945910 & 3.040706 & 2.197225 & 3.010128 & 4.638605 \\
Std. Dev. & 0.000000 & 2.622492 & 0.693147 & 1.068153 & 4.575638 \\
Skewness & 0.592583 & 0.150901 & 0.481272 & 0.674252 & 0.023366 \\
Kurtosis & -0.813654 & 0.364089 & -0.066291 & -0.152584 & 0.348266 \\
Jarque-Bera & 2.974691 & 1.672465 & 1.896712 & 1.821052 & 1.586263 \\
Probability & 1.103654 & 0.955246 & 0.514509 & 0.617935 & 1.034921 \\
Sum & 0.575897 & 0.620256 & 0.773171 & 0.734204 & 0.596032 \\
Sum Sq. Dev. & 12.51415 & 28.26922 & 14.90002 & 19.96904 & 46.02391 \\
Observations & 3.160389 & 0.204940 & 2.084601 & 4.091547 & 0.004914 \\
\hline
\end{tabular}

Table 1 is showing descriptive analysis of the exports statistics.

Table 2. Correlation matrix

\begin{tabular}{cccccc}
\hline & LOG(ET) & LOG(FIC) & LOG(GDP) & LOG(INF) & LOG(RER) \\
\hline LOG(ET) & 1.000000 & 0.501169 & 0.474570 & -0.311371 & -0.392731 \\
LOG(FIC) & 0.501169 & 1.000000 & 0.395813 & 0.356067 & 0.149703 \\
LOG(GDP) & 0.474570 & 0.395813 & 1.000000 & 0.187706 & 0.095605 \\
LOG(INF) & -0.311371 & 0.356067 & 0.187706 & 1.000000 & 0.162524 \\
LOG(RER) & -0.392731 & 0.149703 & 0.095605 & 0.162524 & 1.000000 \\
\hline
\end{tabular}

Table 2 is showing correlation matrix of the exports statistics.

Table 3. Regression analysis

Dependent Variable: LOG(ET)

Method: Least Squares

Date: 05/22/13 Time: 14:41

Sample: 20012010

Included observations: 10

\begin{tabular}{|c|c|c|c|c|}
\hline Variable & Coefficient & Std. Error & t-Statistic & Prob. \\
\hline $\mathrm{C}$ & 45.37916 & 22.69384 & 1.999624 & 0.1020 \\
\hline LOG(FIC) & 2.376060 & 0.867049 & 2.740401 & 0.0408 \\
\hline LOG(GDP) & 0.462246 & 0.257936 & 1.792091 & 0.1331 \\
\hline LOG(INF) & -0.463003 & 0.182065 & -2.543064 & 0.0517 \\
\hline LOG(RER) & -10.99621 & 4.961993 & -2.216087 & 0.0775 \\
\hline \multicolumn{4}{|c|}{ Mean dependent var } & 1.251415 \\
\hline Adjusted R-squared & 0.668290 & \multicolumn{2}{|l|}{ S.D. dependent var } & 0.592583 \\
\hline S.E. of regression & 0.341294 & \multicolumn{2}{|l|}{ Akaike info criterion } & 0.994706 \\
\hline Sum squared resid & 0.582407 & \multicolumn{2}{|l|}{7 Schwarz criterion } & 1.145999 \\
\hline Log likelihood & 0.026470 & \multicolumn{2}{|l|}{ Hannan-Quinn criter. } & 0.828738 \\
\hline F-statistic & 5.533035 & \multicolumn{2}{|l|}{ Durbin-Watson stat } & 3.490750 \\
\hline Prob(F-statistic) & 0.044309 & & & \\
\hline
\end{tabular}


Table 3 is showing regression model and explaining relationship between the dependent and independent variables.

Regression model is showing that probability of fixed investment capital is 0.04 which is less than 0.05 , showing that fixed investment capital is having significant relationship with exports of Pakistan, gross domestic product is showing insignificant relationship with exports of Pakistan with 0.133 probability level which is higher than 0.05, while inflation is showing negative significant relationship with exports of Pakistan with 0.05 probability, and relative exchange rate is showing insignificant relation with the dependent variable with probability of 0.077 , R-square is showing that 81 percent of the variation of dependent variable exports is being explain by the independent variables, and F-statistics is having probability of 0.044 which is less than 0.05 , so overall model is fit.

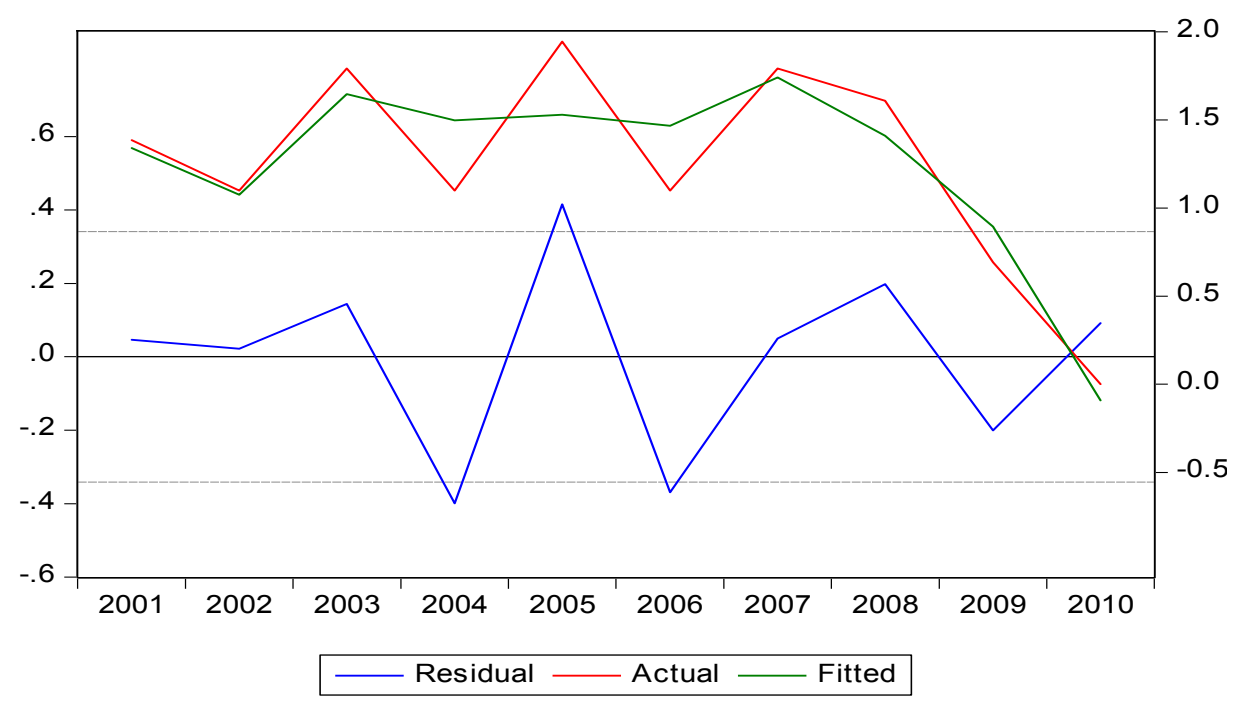

Figure 1. The above graph is showing the relationship between exports and its independent variables

\section{Conclusion \& Policy Implication}

This study investigated the relationship between four independent variables of fixed investment capital, gross domestic products, inflation and relative exchange rate and exports of Pakistan as an independent variable, as per the appearance of the model the study find out that two concerned variables of inflation and fixed income capital owing significant and desired results, while on the other hand the results of the other two variables of gross domestic product and relative exchange rate are showing insignificant effect on exports of Pakistan.

On the basis of the of the findings, this can be suggested that Pakistan should focus to decrease the inflation rate for the purpose to increase exports and on the other hand increase of fixed investment capital can help to boost up and flourish the exports of the country.

State of the art and as per the international quality assurance standards, training institutions for exporters can be developed, which helps to give guidance to enter into the international market passage to meet the challenges.

For the purpose to develop exports oriented and generation culture, revival of era of governmental initiative of "Exports voucher and bonus scheme "can be plug back and through facilitation, incentives and bonuses, specially for untapped or ignored commodities and sectors would be able to create a radical and tremendous change and can help to buildup the exports confidence and encouragement among the investors and contribute for the economic development of Pakistan through cross border trading and exports

\section{Direction for Further Research}

The above mentioned research has been conducted on a very limited scale, and time series data of ten years have been used for analysis, in order to increase the scale in the long run the horizon of the time series data can be extended, If data sample size will increase, then the effect of GDP and RER would be different as per the current 
study is showing, and further work on other variables such as domestic savings, service and goods manufacturing growth rate and others would be helpful to represent a better and complete picture of the results.

A comparison of the growth rate of exports of Pakistan with the neighboring and regional countries helps to give the better picture of the pros and cons of the exports situation of the country, another implication related to the exports of Pakistan can focus on the reasons behind the shifting of Pakistani manufactures to Dubai, Bangladesh etc

\section{References}

Amjad, G., \& Mahmood. (2012). Exports Barriers in Pakistan: Results of a firm -level survey. Lahore Journal of Economics, 17, 103-134.

Shirazi. \& Manap, N. (2005). Export-Led Growth Hypothesis: Further Econometrics Evidence from South Asia. Developing Economics, 4, 472-488.

Shahbaz, A., \& Ahmed. (2011). Exports-Led Growth Hypothesis in Pakistan: Further Evidence. Asian Economics Review, 1(3), 182-197.

Hamid \& Hayat. (2012). The Opportunities and pitfalls of Pakistan Trade with China and other neighbours. Lahore Journal of Economics, 17, 271-292.

Okpara, J. (2009). Entrepreneurial Orientation and Exports Performance: Evidence from an Emerging Economies. International Review of Business Research Papers, 5(6), 195-211.

Bader, S. (2006). Determining Imports of Exports for Pakistan. State Bank of Pakistan Annual Research Bulletin, 2(2), 363-381.

Hussain. (2012). Pakistan Exports Demands: An Analysis. State Bank of Pakistan Research Bulletin, 6(2), 1-13.

Khattak, M. A., \& Umair. (2011). SME's Export Problems in Pakistan. Journal of Business Management, 2(5), 192-199.

Aslam, M., \& Qaisrani. (2002). T unstability, Investment and Economic Growth in Pakistan. Pakistan Economic \& Social Review, 16(1), 57-73.

Allaro, B. (2011). Exports Performance of Oil Seeds and its Determinants in Ethiopia. Journal of Oilseeds, 2(1), $1-15$.

Aurangzeb. (2006). Exports Productivity and Economic Growth in Pakistan: A time Series Analysis. The Lahore Journal of Economics, 11(1), 1-18

Kiran, R., \& Mishra, S. (2011). Research, Exports and Patenting in the Indian Pharmaceutical Industry post Trips Analysis. Journal of Business and Economics, 4(7), 53-67.

Alam, M. (2011). An Econometrics Analysis of Exports-Led-Growth Hypothesis: Reflections from Pakistan. Interdiciplinary Journal of Contemporary Research in Business, 2(12), 329-338.

Ekanayake. (1999). Exports and Economic Growth in Asian Countries: Co integration and Error-Corrrection Models. Journal of Economics Development, 24(2), 43-56.

\section{Copyrights}

Copyright for this article is retained by the author(s), with first publication rights granted to the journal.

This is an open-access article distributed under the terms and conditions of the Creative Commons Attribution license (http://creativecommons.org/licenses/by/3.0/). 